\title{
Economic importance of point thermal bridges to buildings with steel casing
}

\author{
Pavlína Charvátová ${ }^{1, *}$, and Roman Šubrt ${ }^{2}$ \\ ${ }^{1}$ The Institute of Technology and Business in České Budějovice, 37001 České Budějovice, Czech \\ Republic \\ ${ }^{2}$ Energy Consulting, z.s. Alešova 21, 37001 České Budějovice, Czech Republic
}

\begin{abstract}
Point thermal bridges are usually overlooked, their influence on the building's energy may be significant. For warehouses, production and wholesale halls, the usual perimeter construction is a lightweight construction with thermal insulation between two sheets. As a thermal insulation in a significant number of cases, PUR, resp. its PIR modification. Recently, however, systems using thermal insulation of mineral wool are preferred. These structures, however, have both point and linear thermal bridges. In this paper, we focus on differences in the heat transfer coefficient calculated more precisely by using the ideal 1D, 2D and $3 \mathrm{D}$ model fragments and their comparison with the values reported by some manufacturers / vendors. At the end of the paper, we are devoted to quantifying the economic difference between the "offered" state and the fact determined by a more accurate calculation.
\end{abstract}

\section{Introduction}

Nowadays, there is often a steel casing of industrial buildings made of steel plates with inserted thermal insulation mineral wool. This solution is significantly cheaper than the use of sandwich panels of thermal insulation of PIR (PUR) foam, and also these panels significantly less burden on the environment, as it is very simply dismantle them to secondary raw material. Schema of this solution, see Fig. 1.

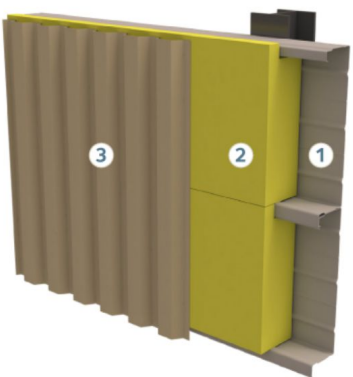

Fig. 1. Schema of systemic heat-insulated sheathing of mineral wool: 1 - carrying "C" casket, 2 inserted thermal insulation of MW, 3- outer steel casing

*Corresponding author: charvatova@mail.vstecb.cz 
In calculating the coefficient of thermal conductivity should be considered with linear point heat bridges. At the same time it is necessary to meet the requirements for thermal protection of the building according to the relevant standards. It would appear that the use of the values indicated by the manufacturer or the supplier of the system is sufficient. However, as revealed by the detailed calculation, the difference of the values found against the manufacturer's stated properties is significant. We were interested in the product of Arcelor Globalwall. In this product were given following values mentioned in Table 1.

Table 1. Arcelor Mittal product Globalwall

\begin{tabular}{|c|c|c|c|c|c|c|}
\hline $\begin{array}{c}\text { Height of "C" casket } \\
{[\mathrm{mm}]}\end{array}$ & 130 & 150 & 160 & 130 & 150 & 160 \\
\hline $\begin{array}{c}\text { Thickness of mineral } \\
\text { wool in total [mm] }\end{array}$ & 160 & 180 & 200 & 210 & 220 & 240 \\
\hline $\begin{array}{c}\text { Coefficient of heat } \\
\text { transmission } \\
\mathrm{U}\left[\mathrm{W} / \mathrm{m}^{2} . \mathrm{K}\right]\end{array}$ & 0,282 & 0,254 & 0,255 & 0,194 & 0,191 & 0,175 \\
\hline
\end{tabular}

\section{Calculation of the coefficient of heat transmission}

In the calculation, we divided the structure into 3 separate sections according to the characteristic heat guiding, namely on a flat surface where the heat conduction is $1 \mathrm{D}$, the "nose" of the cassette where the heat conduction is in 2D and around the screws where the heat conduction is in 3D. Eventually, respective computational program have been used for calculations of these individual models QuickField 5.6 and the results were then summarized as described in the ČSN EN ISO 10211 [1].

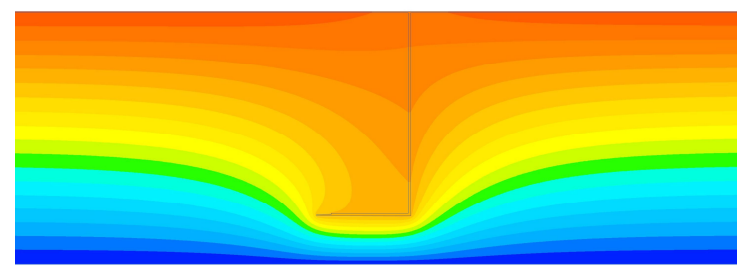

Fig. 2. Simulation of heat distribution on linear thermal bridge (Height of "C" casket $130 \mathrm{~mm}$, Thickness of mineral wool in total $160 \mathrm{~mm}$ )

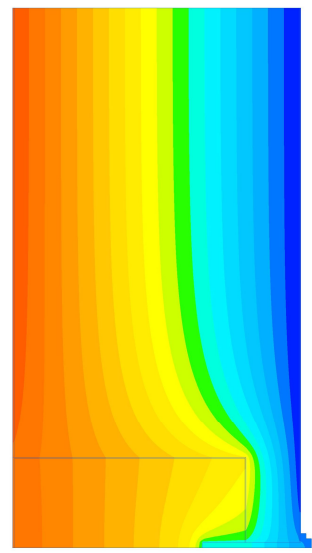

Fig. 3. Simulation of heat distribution on point thermal bridge (Height of "C" casket $130 \mathrm{~mm}$, Thickness of mineral wool in total $160 \mathrm{~mm}$ ) 
Calculation of the coefficient of heat transmission above and can be generally written as follows:

$$
U 3 D=U 1 D+\psi / d-\psi^{*} n * 0,06+\chi^{*} n
$$

(based on equation (12) referred to in v ČSN EN ISO 10211 [1]) where:

$U_{I D}$ The coefficient of heat transmission calculated in one-dimensional terms $\left[\mathrm{W} /\left(\mathrm{m}^{2} . \mathrm{K}\right)\right]$

$\psi \quad$ linear transmittance heat $[\mathrm{W} /(\mathrm{m} . \mathrm{K})]$

$d \quad$ with of the casket [m]

$n$ number of screws on $1 \mathrm{~m} 2$ of construction [-]

0,06 length of the nose of the casket, counted in point coefficient of heat transmission $[\mathrm{m}]$

$\chi \quad$ point coefficient of heat transmission $[\mathrm{W} / \mathrm{K}]$

Calculations have been carried out for different caskets with different thickness of thermal insulation. Results of calculations are set out in table 2.

Table 2. Calculation of point and linear heat transfer factors and heat transfer coefficients

\begin{tabular}{|c|c|c|c|c|c|c|}
\hline Height of "C" casket [mm] & 130 & 150 & 160 & 130 & 150 & 160 \\
\hline $\begin{array}{c}\text { Thickness of mineral wool } \\
\text { in total [mm] }\end{array}$ & 160 & 180 & 200 & 210 & 220 & 240 \\
\hline $\begin{array}{c}\text { linear transmittance heat } \psi \\
{[\mathrm{W} /(\mathrm{m} . \mathrm{K})]}\end{array}$ & 0,072 & 0,066 & 0,055 & 0,032 & 0,035 & 0,033 \\
\hline $\begin{array}{c}\text { heat transfer coefficient } \\
\text { U1D without thermal } \\
\text { bridges [W / (m2.K)] }\end{array}$ & 0,223 & 0,199 & 0,179 & 0,171 & 0,164 & 0,150 \\
\hline $\begin{array}{c}\text { point coefficient of heat } \\
\text { transmission } \chi[\mathrm{W} / . \mathrm{K}]\end{array}$ & 0,0172 & 0,0172 & 0,0172 & 0,0172 & 0,0172 & 0,0172 \\
\hline
\end{tabular}

\section{Comparison of the results}

If we do the calculations on the basis of used calculations comparison of made out values by using the linear and point thermal bridges and values declared by the system supplier, we found substantial differences.

Pro For final calculations, it is necessary be aware of 2 further facts. The width of casket is $600 \mathrm{~mm}$ and also we use for mounting 5 to 7 screws used 5 to 7 to $1 \mathrm{~m} 2$ (under wind loading).

A comparison of the results is shown in Table 3.

Table 3. U3D heat transfer coefficient for the casket width $600 \mathrm{~mm}$

\begin{tabular}{|l|l|l|l|l|l|l|}
\hline Height of "C" casket [mm] & 130 & 150 & 160 & 130 & 150 & 160 \\
\hline
\end{tabular}




\begin{tabular}{|c|c|c|c|c|c|c|c|}
\hline $\begin{array}{c}\text { Thickness of mineral wool } \\
\text { in total }[\mathrm{mm}]\end{array}$ & 160 & 180 & 200 & 210 & 220 & 240 \\
\hline Number of screws & \multicolumn{5}{|c|}{$\mathrm{U}$ heat transfer coefficient for the casket width } \\
\hline $\left.\mathrm{W} /\left(\mathrm{m}^{2} . \mathrm{K}\right)\right]$
\end{tabular}

\section{The economic impact of thermal bridges}

The results show the values of the coefficient of thermal conductivity are significantly lower than actual. The question is, how this deterioration articulates economically. In general, the more heating costs depend on the number of years considered, the heat, the temperature and specific climatic conditions on location. Actually it is about "shared knowledge resource for information" [4] about economic impacts of the solution.

If we neglect the individual variables such as price heat change over time and cost of money, that generally define addiction price spent on heating of the heat transfer coefficient as follows:

$$
M=\Sigma T i * \Delta \theta i * P * U / 1000
$$

where

$M$ is the total amount of money

$T$ is the time for which the considered temperature is valid

$P$ is cost of energy in $\mathrm{CZK} / \mathrm{kWh}$

$U$ is coefficient of heat transmission

Increased costs are the difference of amount of investment money considered without influence of thermal bridges and with calculation of thermal bridges. In the above equation may be modified as follows:

$$
\begin{aligned}
& M=\Sigma T i * \Delta \theta i * P *(U 2-U 1) / 1000 \\
& M=\Sigma T i \Delta \theta i * * P * U / 1000
\end{aligned}
$$

As to the above mentioned, the climatic conditions in the Czech Republic and temperature heating $+20^{\circ} \mathrm{C}$, every increase in the coefficient of heat transmission of $\Delta U=$ $0,01 \mathrm{~W} /\left(\mathrm{m}^{2} . \mathrm{K}\right)$ represents the increase in the consumption of energy for heating of $1 \mathrm{kWh}$ per $1 \mathrm{~m}^{2}$ of structure. Unless the declared value coefficient of heat transmission $\mathrm{U}=0,282$ $\mathrm{W} /\left(\mathrm{m}^{2} . \mathrm{K}\right)$, but in fact the detailed calculation (after simple calculations) coefficient of heat transmission has its value $\mathrm{U}=0,407 \mathrm{~W} /\left(\mathrm{m}^{2} . \mathrm{K}\right)$ this difference means $0,125 \mathrm{~W} /\left(\mathrm{m}^{2} . \mathrm{K}\right)$. The increase in heat consumption means $12,5 \mathrm{kWh} / \mathrm{m}^{2}$. In the usual price heat CZK 1,50 to 3,00 . It represents an increase of annual heating costs by CZK 18,75 to $37,5 \mathrm{CZK} / \mathrm{m}^{2}$. If we keep the costing and pricing order [2], where table 7 is possible life in the range of 30 to 
80 years (flashing) and determine the structure of 60 years, then the increase in the costs of heating structure $1 \mathrm{~m}^{2}$ of CZK 1125 to 2250 .

Also it is very important to keep in mind overall expenses during life cycle. As Nývlt [3] writes "All expenses in the first phases (project costs, cost of new materials, cost of the quality of delivery) will or may be assessed and better understood in long time horizon. There are also barriers and obstacles in using the BIM model, how people together with new technology may overcome these risky issues is other crucial point. BIM also can help in optimization of materials and energy use and minimization of negative impact on environment" and we must admit, that proper solution of thermal bridges at first phases of the particular project will significantly contribute to life cycle efficiency of the building.

\section{Conclusions}

System thermal bridges must always be taken into account when calculating the heat transfer coefficient. It would appear sufficient to monitor the manufacturer / supplier of the relevant material or system and to use the technical parameters stated by them. However, as we have found in a more detailed calculation of the perimeter structure, manufacturers may present untrue information that may lead to significant differences in the properties of the entire structure. Needless to say, “industry's expectations are neither readily nor necessarily matched by reality" [5], and hence the deterioration of the heat transfer coefficient U from the declared value to the real one as shown in Table 2 represents a significant deterioration of the expected parameters of the entire structure. Worsening roughly of $30 \%$ is very important and may lead to further construction problems, such as lower heating.

In conclusion, it is necessary to point out that the case solved by us presupposes the ideal design, i.e. the sealing of the thermal insulation boards both to themselves and to the steel casket. It is possible to assume that non-destructive realization will create further, nonsystemic thermal bridges, which will further deteriorate the structure of the structure. In the case of impending trials, it will be very difficult to prove whether the impact of thermal bridges created during the implementation is more significant than the mistaken consideration of system thermal bridges.

\section{References}

1. ČSN EN ISO 10211 Thermal bridges in building structures - Heat flows and surface temperatures - Detailed calculations (2018)

2. Decree No. 441/2013 Coll. to implement the Property Valuation Act (Valuation Decree)

3. V. Nývlt, Central Europe towards Sustainable Building, 7, 1438-1444 (2016)

4. P. Podmanický, V. Nývlt. International Multidisciplinary Scientific GeoConference Surveying Geology and Mining Ecology Management, SGEM 2015 2(6), 377-384, (2015)

5. V. Nývlt, K. Prušková, IOP Conf. Ser. : Mater. Sci. Eng. 245, 042070 (2017) 